\title{
Del Dios omnipotente a «la humildad de Dios». Una reflexión sobre la evolución en perspectiva kenótica*
}

Olga Consuelo Vélez Caro**

\section{Resumen}

Frente a la comprensión moderna del universo como proceso en evolución, los cristianos se preguntan cómo articular la imagen del Dios creador todopoderoso con los desarrollos científicos. Un intento de respuesta es el que se presenta en este artículo postulando la kénosis divina como punto de partida para hablar de un Dios humilde, autolimitado, solidario con el sufrimiento inherente a la evolución, de manera que su acción creadora se haga compatible con el proceso evolutivo del cosmos, respetando su autonomía propia y posibilitando una experiencia de fe que no se vive al margen de la ciencia sino, por el contrario, que asume sus resultados y descubre el sentido teológico que encierran. El artículo termina explicitando la perspectiva de género que ayuda a recuperar el sentido más profundo de la kénosis divina como entrega y donación desde la plena posesión de sí, evitando un mal entendido abajamiento o sumisión que ha vulnerado la dignidad y autoestima, especialmente de las mujeres. La kénosis cristológica y

Expresión tomada del libro de John F. Haught, Cristianismo e ciência. Para uma teologia da natureza (São Paulo: Paulinas, 2010), 69.

** Doctora en Teología por la Pontifícia Universidade Católica de Rio de Janeiro. Profesora Titular de la Pontificia Universidad Javeriana de Bogotá, Colombia. Contacto: ocvelez@javeriana.edu.co. 
trinitaria es también kénosis en la creación respondiendo así al plan divino de salvación de recapitular todo en Cristo.

\title{
Palabras clave
}

Kénosis, humildad, creación, autolimitación, género.

\section{From Almighty God to "the humility of God." A reflection on evolution in Kenotic perspective}

\begin{abstract}
In front of the modern understanding of the universe like process in evolution, Christians wonder about how to articulate the image of almighty God with the scientific developments. This article intents to answer it by proposing the divine kenosis as a starting point to talk about a humble, self-limited God; a God supportive with the suffering inherent to the evolution; so that his creator-action becomes compatible with the evolutionary process of the cosmos with respect to its own autonomy and making possible an experience of faith, by considering the scientific advances to discover the theological aspects involved within them. The last part of this article is about kenosis and gender perspective because it is important to recover the meaning of kenosis as donation and love but that it is not synonymous of a destructive self-sacrifice, especially from women. The Christological and Trinitarian kenosis are ways to approximate to the divine plan of salvation of recapitulating all things in Christ.
\end{abstract}

\section{Keywords}

Kénosis, humility, creativity, self-restraint, gender. 


\section{Introducción}

La ciencia moderna nos está sorprendiendo con una concepción del universo que desestabiliza las nociones adquiridas. Más aún, para los creyentes, las conclusiones científicas cuestionan profundamente la fe en el Dios omnipotente artífice de esta creación y garante de su sustentabilidad y nos invitan a preguntarnos si todavía se puede creer en el Dios bíblico que hizo el mundo en siete días como relata el libro del Génesis (1,1-2,3).

Pero esa invitación es más que eso. Es un imperativo que se impone para poder mantener la significatividad del mensaje revelado en el momento actual y validar su pertinencia para los varones y mujeres de hoy. Es por eso que autores como John Haught emprenden esa ingente tarea y los caminos abiertos por él y otros autores nos convocan a continuarlos. Uno de esos caminos señalados por Haught es la humildad de Dios o su Kénosis divina. Este autor advierte que concebir a Dios desde esas características puede llevarnos a articular correctamente la fe en el Dios creador del universo con la concepción moderna de la cosmología. Otros autores hacen planteamientos que corroborarían esa tesis al hablar de "la creación como Kénosis"1.

En este artículo pretendemos desarrollar esa argumentación, valiéndonos de los aportes de algunos de estos autores con el objetivo de explicitar esta realidad divina que, sin ser desconocida, posiblemente no ha sido suficientemente asumida, en la reflexión y en la experiencia cristiana. Nadie dudaría del valor de la humildad, como actitud humana, capaz de introducirnos en la dinámica del Reino, pero a muchos les cuesta concebir a Dios desde esa perspectiva. Afirmar un Dios humilde, kenótico, sin poder, es privarlo de sus atributos filosóficos de omnipotencia u omnisciencia y quedarnos con un Dios débil y frágil, demasiado humano, encarnado -se podría

1 Una colección de artículos en esta línea los encontramos en la obra de John Polkinghorne (ed.), La obra del amor. La creación como kénosis (Estella-Navarra: Verbo Divino, 2008). Estos artículos constituyen uno de los insumos fundamentales de esta reflexión. 
decir irónicamente-, que no nos atrae seguir, máxime si tenemos en cuenta tantas debilidades personales y sociales que a diario constatamos y de las que buscamos liberarnos desde un poder mayor que lo haga posible. Ahora bien, tenemos que anotar que este tema no está suficientemente estudiado, ni asumido, y lo que digamos aquí se sitúa más en la línea de hipótesis y búsquedas, que en logros o certezas adquiridas. Al referirnos a los autores aquí estudiados, buscamos presentar su pensamiento y explicarlo lo más claramente posible pero, en ningún caso, estamos comprometiéndonos con esos planteamientos o proponiendo sus conclusiones como respuestas válidas a estas cuestiones.

Desde este horizonte, en este texto nos referimos, en primer lugar, a las dificultades para el diálogo fe-ciencia que implican la imagen de Dios creador que tenemos en nuestra cosmovisión religiosa. En un segundo momento, valiéndonos de los aportes de distintos autores, mostraremos cómo al recuperar la kénosis divina, nos introducimos en un diálogo posible entre fe y ciencia. Haremos una referencia a la perspectiva de género por ser ésta una instancia de análisis que se ha confrontado con la categoría kénosis por la realidad problemática que supone esta última, frente al empoderamiento de las mujeres ${ }^{2}$. Finalmente esbozaremos algunas conclusiones que nos permitan seguir abriendo caminos al diálogo entre la autonomía del mundo y la fe en el Dios creador de cielo y tierra.

\section{Dificultades para el diálogo fe-ciencia}

La ciencia moderna afirma que el universo es "una narrativa en proceso" ${ }^{\prime 3}$. No era ese, ni aún lo es, el pensamiento de la mayoría de los cristianos quienes al acercarse a leer los pasajes del Génesis donde se narra la creación del mundo, creen que ese acontecimien-

2 Amparo Novoa y Consuelo Vélez, "La categoría kénosis. Una lectura desde la perspectiva de género", Theologica Xaveriana 169 (2010): 159-190.

3 John Haught, Cristianismo e ciência. Para uma teologia da natureza. São Paulo: Paulinas, 2010. 
to maravilloso tuvo un tiempo determinado -siete días- los cuales, al finalizar, concluyeron con la creación. A partir de entonces, solo cabe esperar el devenir de la historia de salvación en la cual cada ser humano se juega su futuro definitivo dependiendo de la capacidad de responder que tenga frente al Creador. Más aún, considerado el planeta tierra como centro y sentido de toda la creación, costó "sangre"4 la aceptación de un cosmos donde la tierra no fuera el centro de la creación sino que girara alrededor del sol junto con otros planetas situados en ese mismo sistema solar. Y, más aún, que éste no fuera el único sistema solar sino que existiera un multiuniverso que nuestras mentes, posiblemente, no alcanzan a imaginarlo en su concreción y magnitud.

Pero antes de indagar por las dificultades entre ciencia y fe hemos de tomar conciencia de un hecho decisivo. La ciencia nos puede decir el qué, cómo y cuándo de los acontecimientos naturales. Pero no puede aportarnos el sentido último de la realidad ni su origen como "obra del amor" . La fe, por el contrario, solo puede hablarnos del para qué, del sentido último, de la razón de ser de la vida humana y de toda la creación. ¿̇Cómo entonces pretender que dos tipos de preguntas distintas entren en diálogo? De aquí surgen las diferentes posturas en boga actualmente.

Por una parte, tenemos aquellos que solo admiten una de esas preguntas -bien sean las preguntas científicas o las preguntas religiosas- y no se interesan por las otras. Aunque esta postura evita el conflicto, no soluciona el problema frente al cual la mente humana exige un mínimo de respuestas y/o de articulación de los dos ámbitos. Por otra parte, encontramos los que también se colocan en uno de los dos horizontes pero no ignoran el contrario sino que, precisamente, se dedican a negarlo, con base en la postura que asumen. castigados e incluso matados por proponer nuevas concepciones científicas que afectaban, principalmente, las creencias religiosas vigentes hasta entonces.

5 Sugestivo título del libro colectivo de John Polkinghorne al que ya hicimos referencia y nos ha servido de base para gran parte de nuestra reflexión. 
Esta postura provoca conflicto porque se ataca de frente la posición contraria. La teoría creacionista o el ateísmo científico responden a esta posibilidad. Aquí naturalmente se encuentran los orígenes de los enfrentamientos irreconciliables que solo llevan a la violencia, a la intolerancia y al rechazo de unos frente a otros. Finalmente están los que buscando "un punto de vista superior "6 posibilitan el diálogo y, sin pretender unificar, aspiran a ofrecer una respuesta más amplia, integradora, que contribuya decisivamente al bien y a la verdad humana. John Haught se refiere a esta postura como una "explicación escalonada"7 que consiste en dar espacio a diferentes comprensiones de un mismo fenómeno. Así es posible dar una explicación desde la ciencia y otra desde la teología, reconociendo sus diferencias pero buscando sus puntos de articulación y complementación. Puede que algunos se resistan a admitir esa explicación escalonada pero estaría muy bien que, como personas creyentes, nos mostremos abiertos y receptivos a buscar caminos de respuesta, sabiendo que la explicación científica aporta elementos que pueden ser integrados por la fe y que es responsabilidad nuestra asumirlos y promoverlos.

Pero íqué es lo que en realidad se opone a la fe desde los descubrimientos modernos? Cabe anotar que no son los descubrimientos en sí, sino las consecuencias que se derivan de ellos. Fenómenos nuevos como la teoría del Big Bang, la evolución, el código genético, el campo profundo de Hubble o los aspectos químicos de la mente no deberían inhabilitar la dimensión trascendente del ser humano sino, por el contrario, profundizar en ellos y ver la iluminación que ofrecen a las preguntas sobre el origen y sentido del cosmos y de la vida, reconociendo que esos descubrimientos exigen más inteligencia y razonabilidad tingue varios tipos de dialéctica: genética, complementaria y opuesta. Afirma que las dos primeras se resuelven al comprender que los polos distintos que se presentan, son diferentes momentos de un proceso (genética) o puntos de vista complementarios de la misma realidad (complementaria). Pero la tercera, la dialéctica de opuestos solo puede superarse proponiendo "un punto de vista superior" que sin dejar de tomar en cuenta los elementos opuestos, ofrezca una nueva síntesis que sea capaz de articular lo diferente, lo complejo, lo distinto. Bernard Lonergan, Método en Teología (Salamanca: Sígueme, 1994), 229-231. John Haught, op.cit., 200. 
frente a todo lo creado. Sin embargo, muchos pretenden responder a estos interrogantes desde lo material, lo físico, lo natural. Es decir, no admiten otra realidad más que la naturaleza sin dejar ningún espacio a lo divino. A eso se le llama naturalismo científico. De aquí podemos afirmar con Haught: "no es la ciencia, sino un tipo de naturalismo materialista frecuentemente confundido con ciencia, lo que entra en conflicto con las creencias del cristianismo y de otras religiones"8.

Pero precisamente aquí está la parcialidad de este planteamiento científico, porque al no admitir otras causas más que las naturales para explicar la realidad se deja de lado el mundo psíquico y afectivo de los seres humanos y, más aún, la pregunta religiosa que, como pregunta legítima, está inserta en el cuestionar humano ${ }^{9}$. Por eso una "teología de la naturaleza"10 propone que hay más cosas en el mundo que lo que aparentemente se ve y la ciencia no puede abarcarlas todas. Este espacio es el que bien puede ocupar una teología, no porque se vayan a revelar cosas extraordinarias, sino porque en ese devenir natural, Dios se manifiesta y es la fe la que puede descubrir esa presencia en los mismos elementos en los que la ciencia descubre una causalidad y una transformación natural. En otras palabras, la fe en el Dios creador no crece y madura negando los aportes de la ciencia sino descubriéndolo en el desarrollo y progreso científico.

La problemática que está en juego en esta dificultad de conciliar fe y ciencia radica en la imagen de Dios que tenemos. El relato bíblico entendido literalmente, ha presentado un Dios todopoderoso capaz de separar las aguas y crear los cielos y los océanos, de hacer surgir la luz de la oscuridad, crear las estrellas y el firmamento y hacer brotar la vida en las diferentes especies. Y como sumo momento de su creación, capaz de crear al ser humano a su imagen, creación que siguiendo el texto de Génesis 2, es tan material y concreta, como soplar con su

\footnotetext{
Ibíd., 29.

Bernard Lonergan, op. cit, 103-105.

Es la respuesta teológica al naturalismo científico que presenta Haught en su libro. John Haught, op. cit., 61.
} 
espíritu divino el barro, sacando de este un ser humano inteligente. Todo es armonía y realización plena en esta creación y parece que Dios no tiene otro quehacer más que contemplarla, velando porque el ser humano no pretenda ser como Él. Viendo la creación de esta manera, se entiende por qué Dios les advierte a Adán y a Eva sobre el castigo que acarrea probar el fruto "del árbol de la ciencia del bien y del mal" (Gn 2,17). En otras palabras, es un Dios que hizo su creación de una vez para siempre y ahora está sentado viendo el devenir de esta, esperando que la libertad humana secunde su plan de salvación hasta que él mismo decida terminarla y permita que los seres humanos compartan su misma vida.

Una lectura bíblica de ese estilo y una teología que respalde tal concepción de creación, no pueden dialogar con los descubrimientos de la ciencia moderna sobre el origen del mundo y de la vida. No hay encuentro posible. Por eso, solo quedan dos caminos: o se rechazan los planteamientos de la ciencia o se purifica la imagen que se tiene de Dios. Esta segunda opción es la más acertada si no se quiere caminar paralelo a la ciencia, limitando así la fe a la esfera personal sin articularla con todas las dimensiones humanas, especialmente, la científica. Pero żacaso podemos cambiar de imagen divina para solucionar nuestras dificultades? Esta sería una objeción válida si no encontráramos en la misma revelación una respuesta a tal objeción.

La imagen de un Dios todopoderoso ha sido la tentación constante del pueblo elegido y solo la conversión hacia el verdadero Dios de Israel le ha permitido continuar su historia hasta nuestros días. Veámoslo brevemente. La imagen del Dios que salvó al pueblo de Israel del poder de los egipcios entró en crisis con la experiencia del exilio. ¿Dónde está ese Dios fiel y bondadoso? ¿Qué pasó con sus promesas y su poder? Paradójicamente, es en el desierto donde el pueblo encuentra que el Dios que camina con ellos es el que acompaña su historia y se hace nuevamente presente en la experiencia del exilio. Desde ahí se puede suspirar por la tierra prometida y se encuentran las fuerzas para continuar caminando hacia ella. 
Esa experiencia veterotestamentaria es también la vivencia de la primera comunidad cristiana. Los signos y maravillas realizadas por Jesús "los cojos caminan, los ciegos ven, los sordos escuchan" (Lc $4,16)$-signos con los que Juan Bautista puede reconocer que Jesús es el Mesías esperado (Lc 7,19-23)- pierden todo su valor cuando llega la crucifixión y la muerte. "Dios mío, Dios mío ỉpor qué me has abandonado?" (Mt 27,46) es el grito que se repite en la experiencia cristiana desde aquel primer fracaso hasta nuestros días. Y solamente cuando lo frágil y lo pequeño, cuando la aceptación de la muerte se hace realidad, resurge la vida y la resurrección. Y ese reino que era la pequeña semilla que nadie veía (Mt 13,31-32), comienza a crecer y brota en múltiples y variadas circunstancias. Pero la dinámica del reino continúa su curso y así como las tentaciones de Jesús en el desierto (Lc 4, 1-12) no fueron un único momento en su vida sino el desafío constante que acompañó su misión, la vida cristiana está impregnada de esa misma realidad en muchos y variados acontecimientos.

Los desafíos que hoy lanza la ciencia moderna a la fe nos invitan a instalarnos en esa dinámica para salir bien librados de esta dificultad. Pero no es de extrañar que nos sintamos en profunda crisis. ¿Cómo compaginar la fe en el Dios creador todopoderoso con la certeza de un cosmos y un desarrollo de la vida que está pudiendo ser develada y entendida? Las preguntas sobre el cómo y cuándo parecen responderse. Pero no coinciden con los datos bíblicos. No coinciden con la imagen de Dios que hizo el mundo de la nada y ahora simplemente acompaña su devenir. La crisis es legítima y es urgente encontrar el camino para responder de manera creíble y en sintonía con el mundo actual.

\section{La kénosis como camino de encuentro entre fe y ciencia}

Según describimos en el apartado anterior, los descubrimientos de la ciencia tropiezan con la imagen de Dios todopoderoso creador 
del cielo y de la tierra que profesamos en el credo. A este Dios no le cabe la posibilidad de un universo inacabado, de una evolución que supone "el accidente, la selección natural y un tiempo profundo"11 como condiciones de desarrollo, ni una providencia divina que no puede intervenir directamente en su creación para arreglar las imperfecciones humanas. Pero acaso, ¿̇no es ese mismo Dios bíblico el Dios encarnado, histórico, capaz de salir de sí mismo, abajarse, vaciarse, de no retener su condición divina (Flp 2,5)? Esta es la argumentación que pretendemos seguir aquí apoyándonos en algunos autores que ven este camino como una manera posible de establecer dicho diálogo. Una breve presentación de estos planteamientos, nos permitirá realizar esta reflexión.

\subsection{Teología de la kénosis de Cristo}

No pretendemos aquí presentar esta teología de manera exhaustiva. Basta introducirnos en el tema siguiendo los planteamientos de Jürgen Moltmann ${ }^{12}$ referidos directamente a plantear una relación adecuada entre fe y ciencia. El texto bíblico para referirnos a la kénosis es Flp 2, 5-11 en el que se habla de la condición divina del Hijo de Dios en el cielo de la que se despojó llegando a ser esclavo, crucificado en el Gólgota. No nos detendremos en los problemas exegéticos del texto ${ }^{13}$ sino en las reflexiones teológicas sobre el mismo.

En primer lugar, algunas escuelas de teología protestante entendieron el texto referido a las dos naturalezas de Cristo. La kénosis significa en ese contexto que Cristo al hacerse hombre renuncia a sus atributos divinos -omnipotencia, omnipresencia, omniscienciahaciéndose como cualquier ser humano, pero dejando claro que esa renuncia solo afectaba a su naturaleza humana, no a la divina. Poste-

\footnotetext{
11 Ibíd., 128.

12 Jürgen Moltmann, "La kénosis divina en la creación y consumación del mundo", en John Polkinghorne (ed.), op. cit., 181-196.

13 Para una visión exegética Cf. Gordon D. Fee, (ed.), Paul's letter to the Philippians. The New International Commentary on the New Testament, Michigan: Wn.B. Eerdmans Publisching Co., 1995); Adan, Grelot, "Deux notes critiques sur Philip 2, 6-11", Bíblica 54 (1973): 169-186.
} 
riormente, otras escuelas entendieron el texto referido a la misma condición divina, es decir, al Cristo en su hacerse humano, sustituyendo su naturaleza divina por la humana. Podemos imaginar la cantidad de problemas que estos planteamientos trajeron. Si el Hijo de Dios se hace humano ícómo reconocerlo como Hijo de Dios? Los kenotistas luteranos del siglo XIX respondían haciendo una lista de los atributos divinos y afirmando que Jesús se había despojado de los atributos que tienen relación con el mundo pero mantenía los relacionados con la esencia de Dios: verdad, santidad y amor. Lo que es cierto es que esta división de atributos y esta manera de explicar la kénosis no tuvieron muchos seguidores y se necesitaba otra respuesta.

Hans Urs von Balthasar entendió la kénosis no en el marco de la doctrina de las dos naturalezas sino en el contexto de la doctrina trinitaria ${ }^{14}$. La naturaleza esencial del Hijo eterno es la del ser obediente al Padre, actitud que mantiene en su encarnación al permanecer obediente hasta la cruz. Por tanto, en su condición de esclavo no oculta ni renuncia a su condición divina sino que la está revelando. La kénosis "no es una autolimitación ni una autorrenuncia por parte de Dios sino que es la autorrealización de la autoentrega del Hijo al Padre en la vida trinitaria de Dios. En virtud del amor sin límites, la vida íntima de la Trinidad está marcada por la kénosis recíproca de las personas divinas en su mutuo relacionarse" ${ }^{15}$. Aunque esta interpretación trinitaria de la Kénosis supera las interpretaciones de los kenotistas, no soluciona el problema de los atributos divinos con relación al mundo -entendidos metafísicamente- porque se queda en las relaciones intratrinitarias.

En la teología católica se concibió la kénosis como el Dios hecho humano en Jesús, ocultando su condición divina y también como la forma de existencia del mismo Jesús en su vida histórica ${ }^{16}$.

14 Hans urs von Balthassar, "El misterio pascual", en Mysterium Salutis III, dirigida por Johannes Feiner y Magnus Lohrer (Madrid: Cristiandad, 1971), 143-331.

15 Jürgen Moltmann, op cit., 185.

16 Para profundizar en el significado del Himno a los Filipenses no solo como encarnación del Hijo de Dios sino como manera de existir del Jesús histórico Cf. Amparo Novoa y Consuelo Vélez, op. cit., 159-190. 
Por su parte, en la teología judaica de la shekinah de Dios, se postula el ser kenótico de Dios al proponer su doble presencia tanto en la esfera trascendente como en el mundo: Dios está presente en los cielos y en su exiliado pueblo, es ilimitado y limitado, infinito y finito, está libre del sufrimiento y de la muerte y, a la vez, sufriendo y muriendo con su pueblo ${ }^{17}$.

En esta misma idea de desarrollo teológico sobre la kénosis, la teología está vinculando la idea de kénosis a la creación del mundo y a la presencia de Dios en ella. Por una parte, si libremente Dios decide crear un ser que no es divino, de alguna manera muestra la esencia misma del Creador al permitir que existan seres distintos de Él. Para poder coexistir con un mundo finito se necesita que Dios mismo se autolimite y este acto se interpreta como primer acto de gracia porque la limitación de su infinitud y omnipotencia es ella misma un acto de su omnipotencia: solo Dios puede limitar a Dios. Pero aún se precisa algo más. Que Dios mismo haga espacio para darle cabida a la creación y así pues, "la creación viene a existir en el espacio producido por la kénosis de Dios"18. "Solo allí donde Dios se retira de sí a sí mismo, puede Él producir algo que no sea la misma esencia y ser divinos"19.

La kénosis vinculada a la creación también se interpreta como acto de autohumillación divina que culmina con el sometimiento de Cristo a la muerte en Cruz: "La kénosis que alcanza su clímax paradójico en la cruz de Cristo, empezó ya con la creación del mundo". ${ }^{20}$

La consecuencia lógica de vincular la creación a la kénosis de Dios, es comprender que esa misma kénosis sigue presente en toda la evolución del mundo hasta su consumación. Por eso no es incompatible pensar en un Dios omnipotente en su paciencia sufriente, es

17 Jürgen Moltmann, op. cit., 188.

18 Ibíd., 190.

19 Gershom Scholem, Major Trends in Jewish Mysticism (New York: Schocken, 1954), 117. Citado por Moltmann Jürgen, op. cit., 191.

20 Emil Brunner, Dogmatics, vol.2 (Londres: Lutterwoerth Press, 1952), 20. Citado por Jürgen Moltmann, op. cit., 191. 
decir, en su amor. Esa paciencia de Dios es su poder y de esa manera es que sostiene el mundo con sus dificultades, contradicciones, conflictos, desarrollos. La kénosis se equipara también a la posibilidad que trae el futuro en el cual Dios también está presente no determinándolo sino acompañándolo en su devenir. Precisamente la "meta de la kénosis divina en la creación y conservación del mundo, es ese futuro que nosotros representamos con los símbolos del Reino de Dios y la Nueva Creación, o mundo sin fin"21.

\subsection{Kénosis como humildad de Dios}

La kénosis divina, a la que hicimos referencia anteriormente, se puede entender no solamente referida a las personas y a la historia humana sino también a toda la creación, posibilitando así el diálogo con ese universo en desarrollo que hoy la ciencia nos revela.

El primer tema que nos interesa frente a la creación es el tema del poder. La creación parece implicar un Dios todopoderoso. Sin embargo, la kénosis divina nos muestra otra forma de poder: la del servicio y donación, la de la humildad de Dios. Basta aquí recordar la vida histórica de Jesús en servicio y entrega, de la que el himno a los Filipenses (2,5-11) hace mención. En este mismo sentido, Moltmann afirma: "Hasta para crear el cielo y la tierra, Dios se vació de toda su omnipotencia plena y, como Creador, asumió la forma de siervo"22. No se niega entonces el poder inherente al acto creador sino que se hace comprensible, con esa manera de entender el poder, el origen del universo en el Big Bang y su lento desarrollo por medio de la evolución, la selección natural, la emergencia continua de vida en sus más ricas y variadas formas.

En segundo lugar hemos de abordar el misterio y preguntarnos: si la ciencia va mostrando el cómo de la creación i̇es posible mantener el sentido del misterio que implica la presencia divina? La perspectiva

21 Jürgen Moltmann, op. cit., 196.

22 Jürgen Moltmann, God in Creation. A New Theology of Creation and the Spirit of God (San Francisco: Harper \& Row, 1985), 88. Citado por John Haught, op. cit., 72. 
kenótica nos invita a ese autovaciamiento para distinguir entre lo que no conocemos -objeto de la ciencia- de lo que es experiencia de misterio -objeto de la fe-. Es así como el desarrollo de la ciencia va mostrando progresivamente la constitución y origen del universo. A pesar de todo lo alcanzado es preciso reconocer todo lo que falta. $Y$, al mismo tiempo, justamente ese desarrollo procesual, lento, siempre menor de lo que deseamos, habita en un horizonte de misterio mayor que nos aproxima a la trascendencia y nos hace compatible los avances de la ciencia con la experiencia trascendente. Es así como Einstein afirmaba: "La más bella experiencia que podemos tener es la del misterio. Quien no consigue maravillarse, abismarse, está muerto. Es ese conocimiento y esa emoción que constituye la verdadera religiosidad"23.

La evolución y la Providencia divina también son aspectos que interesan en esta reflexión. ¿ Cómo compaginar la Providencia de Dios con la evolución darwiniana que implica accidentes, selección natural y tiempo profundo? El abajamiento de Dios permite también dar una respuesta: "una teología evolutiva debe retratar el abajamiento de Dios como la inserción en las camadas más profundas del proceso evolutivo, abrazando y sufriendo con toda la narrativa cósmica, no solo en los últimos capítulos humanos"24. Si la teología permanece fiel a sus fuentes reveladoras, también debe encarar el divino abajamiento como el fundamento de la propia creación. Solo este vaciamiento de Dios permite la existencia de un mundo diferenciado de Él. Y es esta separación del mundo respecto a Dios, lo que permite establecer una relación dialógica entre ambos.

Tal vez sea por causa del humilde autodespojamiento de Dios que la receta darwiniana consiste en sus tres ingredientes: contingencia, limitación regular y tiempo abundante. Sin accidentes no habría realmente vida sino una rígida secuencia de acontecimientos. Las

\footnotetext{
23 Albert Einstein, Ideas and Opinions (New York: Modern Library, 1994), 11. Citado por John Haught, op. cit., 45.

24 John Haught, op. cit., 137.
} 
leyes de la naturaleza -incluso la de la selección natural- pueden ser entendidas si se le da al mundo un grado de consistencia, autonomía y autoconfianza de cara a su Creador. Sin leyes todo sería un caos. Además, si la naturaleza es distinta de Dios, ha de atribuírsele tiempo suficiente para que los experimentos evolutivos ocurran en el contexto de la vasta gama de posibilidades que le son disponibles por la infinidad de recursos de su Creador. Aceptar esa independencia del mundo con respecto del Creador, da sentido a estas realidades naturales y hace entender a Dios como aquel capaz de autolimitarse para que surja un nuevo ser con el cual pueda entablar una relación personal. Por tanto, la evolución es del todo congruente con un mundo de libertad emergente, que posibilita un encuentro cada vez más íntimo con Dios.

Una creación originalmente acabada es teológicamente inconcebible porque si Dios desde el inicio hubiera hecho un mundo perfecto, ese mundo sería igual a Dios y, por tanto, no sería una creación. El mensaje radicalmente nuevo del evangelio es que el poder no significa capacidad de manipular sino amor que se dona y es ese amor el que hace posible una creación de la que surge la libertad humana como respuesta a ese amor. La perfección consiste, entonces, no en retornar a un estado ideal que se perdió por el mal humano, sino en un deseo de alcanzar una perfección que se espera encontrar en un futuro posible ${ }^{25}$.

\subsection{Kénosis como autolimitación de Dios}

Si realmente pretendemos ser coherentes con un mundo que se desarrolla autónomamente, según los descubrimientos de la ciencia, hemos de postular un ser divino capaz de mantener la integridad de la naturaleza. Esto es lo que intenta Ian Barbour ${ }^{26}$ al plantear un Dios que se autolimita, interviniendo en su creación no desde fuera como se pensaba antes del desarrollo científico, sino a partir de las 
estructuras y energías existentes en la misma creación ${ }^{27}$. Es decir, Dios actúa sutilmente en cooperación con las fuerzas y estructuras de la naturaleza más que interviniendo unilateralmente. Ya en la tradición tomista se intentó conciliar la omnipotencia divina con la integridad de la naturaleza, diciendo que Dios como causa primera actúa omnipotentemente a través de las causas segundas, que son las de la naturaleza. Este planteamiento fue defendido en tiempos más recientes por Karl Barth y Austin Farrer, entre otros.

Pero no solo el desarrollo de la creación interpela la imagen del Dios que proclamamos. El mayor desafío es explicar la existencia del mal y del sufrimiento presente no solo en los seres humanos sino en toda la realidad de los seres no humanos y, más aún, cuando lo constatamos como inherente al proceso evolutivo: "La historia evolutiva ha requerido lucha y competición, en la que una gran mayoría de especies han llegado a extinguirse" ${ }^{28}$. Pero esta extinción no solo se ha dado en este proceso evolutivo sino que, desgraciadamente, la especie humana ha visto cómo el exterminio puede ser fruto de la voluntad de unos pocos sobre muchos otros. Es el caso del exterminio judío por el nazismo o de las víctimas de múltiples formas de terrorismo en tantas partes del planeta de manera indiscriminada y sin piedad. Ante todo eso żcómo hablar de un Dios omnipotente si parece que no puede evitar el mal?

La teología kenótica ofrece una respuesta no como mera especulación, sino desde la realidad histórica de un Dios hecho ser humano en Jesús, que padece, en su sufrimiento en cruz, un cierto tipo de exterminio e ignominia. En la vida histórica de Jesús, Dios se autolimita mostrando que la voluntad humana puede matar al mismo

27 Este pensamiento lo comparten, entre otros autores, George Ellis (sostiene que Dios determina las indeterminaciones que las leyes de la física cuántica deja abiertas), John Polkinghorne (Dios actúa comunicando "información pura" en los puntos de bifurcación extremadamente sensibles que describe la teoría del caos sin que viole con ello la ley de conservación de la energía) y Arthur Peacocke (Dios actúa con una "causalidad descendente" similar a la influencia que los niveles más altos del interior de un organismo ejercen sobre los componentes de los niveles inferiores estableciendo condiciones, límites y contrastes pero sin violar las leyes del nivel inferior). Cf. Ibíd., 23.

Ibíd., 25. 
Dios. Ese mismo proceso se postula para la creación concebida en términos de evolución. Él acompaña ese proceso tomando en serio la libertad de las creaturas y la evolución del universo, corriendo el riesgo del sufrimiento y del mal, sin que eso suponga dejar de sostener la creación.

Ahora bien, esta autolimitación de Dios no es una posibilidad más, entre otras que Dios tiene, sino que hace parte del ser de Dios entendido como amor ${ }^{29}$. Esa limitación de Dios no es voluntaria sino inherente a la naturaleza divina. Precisamente por eso es posible salvaguardar efectivamente la integridad de la naturaleza y el sentido del dolor, porque solo concibiendo a Dios como metafísicamente autolimitado -valga la pena aclarar que esa limitación de Dios no viene de una causa externa- deja de ser incoherente un Dios que pudiendo evitar el dolor no lo hace o que siendo omnipotente para manejar el curso de la historia, permanece pasivo ante ella. Por tanto, un Dios concebido en términos de autolimitación óntica permite entender una naturaleza en evolución en la que cabe un poder divino no como control dominador sino como potenciación habilitadora ${ }^{30}$.

\subsection{Kénosis como asunción definitiva del sufrimiento implicado en la evolución}

Como acabamos de señalar, la cuestión del sufrimiento es una de las realidades que más golpean la imagen de Dios. Pero si, de alguna manera, el sufrimiento causado por el género humano preserva la omnipotencia divina ya que es fruto de la libertad humana, el sufrimiento que implica la evolución no parece tener la misma explicación. Más aún, ese sufrimiento es inherente al proceso evolutivo y no puede evitarse. ¿Cómo explicar entonces dicho sufrimiento? La autolimitación divina, señalada en el apartado anterior no resuelve

Este mismo planteamiento es el que propone la llamada teología procesual. Esta teología surgió del intento de algunos teólogos de utilizar la filosofía del proceso de Alfred North Whitehead para expresar y reformular las creencias de una tradición religiosa -concretamente de la tradición cristiana-, aunque hay que anotar que algunos pensadores judíos y algunos budistas han propuesto objetivos similares. Cf. Ibíd., 22. 
el problema. Es necesario asumir que Dios acompaña ese proceso evolutivo que tiene como constitutivo el sufrimiento.

Arthur Peacocke ${ }^{31}$ muestra cómo el sufrimiento es inherente a la creación en proceso, al señalar los cuatro rasgos más importantes del proceso evolutivo de la evolución biológica descubiertos por la ciencia actual: (1) continuidad y emergencia; (2) carácter natural y científico; (3) complejidad, información, dolor, conciencia refleja; (4) carácter costoso.

En primer lugar, la evolución biológica es continua y pone de manifiesto la emergencia de nuevas formas de vida. Esto no solo fue afirmado por Darwin y Wallace sino que hoy la biología molecular lo reafirma con el descubrimiento de la universalidad para todos los organismos vivos del ADN, que ha permitido mostrar la lenta pero real continuidad de los procesos de la evolución biológica a lo largo de los casi tres mil millones de años a los que se remontan complejos macromoleculares de los que comenzó a surgir algún tipo de vida. Esos procesos pueden describirse también como manifestaciones de la emergencia, pues a lo largo del tiempo van apareciendo nuevas formas de materia y una jerarquía en la organización de esas mismas formas. Por tanto, esta imagen dinámica de estructuras vivas implicadas en un cambio continuo y sin fin, "excluyen toda concepción estática del modo en que Dios da existencia a todas las cosas existentes y sigue sosteniéndolas y manteniéndolas en el ser (...). Toda noción de Dios como Creador deberá ya afirmar que Dios está creando continuamente, dando de continuo la existencia a lo que es nuevo; que Dios es Semper Creator, que el mundo es una creatio continua"32. Frederick Temple así lo expresó: "podemos decir que Dios no hizo las cosas, sino que hizo que ellas se hiciesen a sí mismas"33. En otras palabras, la evolución nos lleva a tomar con toda radicali-

31 Arthur Peacocke, "El coste de la nueva vida", en John Polkinghorne, op. cit., 45-70.

32 Ibíd., 47

33 Frederick Temple, Conferencias Bampton de 1885 (Michigan: Baker Book House, 1961), citado en Ibíd., 48 
dad la inmanencia de Dios Creador que crea en, y por medio de los procesos del orden natural. Esta postura no es panteísmo porque lo que se identifica con los procesos creativos es la acción de Dios no su ser divino.

En segundo lugar, la evolución biológica procede naturalmente, es decir, con procesos accesibles e inteligibles gracias a la biología y a otras ciencias naturales. Esto significa que no hay necesidad de recurrir a Dios como una especie de factor adicional no accesible científicamente que complemente los procesos creativos del mundo a los que Dios da ciertamente existencia, sino que esos mismos procesos son Dios mismo actuando como Creador. En esos procesos interviene el azar y las leyes naturales permitiendo que emerjan y evolucionen formas nuevas. Si todo estuviera regido por una ley estricta, prevalecería un orden repetitivo y no creativo pero, por el contrario, es esa combinación la que hace posible que exista un universo ordenado capaz de desarrollar en su interior nuevas formas de existencia. Las consecuencias derivadas de estos planteamientos son que Dios es el creador tanto de las leyes como del azar y Él mismo corre el riesgo implicado en el azar, al crear de esa manera.

En tercer lugar, la ciencia se pregunta si se pueden encontrar algunas tendencias significativas en la evolución. Cada vez se piensa menos en la evolución como un árbol en el que el ser humano está en la cúspide para pensarla como "un arbusto que se ramifica copiosamente y que es continuamente podado por el torvo podador que es la extinción, no una escala de progreso predecible"34. Más aún, se habla cada vez más de una creación cuya finalidad no es el ser humano: "Si la humanidad surgió solo ayer como una pequeña ramita de una rama de un árbol floreciente, entonces la vida no puede, en ningún sentido genuino, existir para nosotros o debido a nosotros. Quizás únicamente somos una idea tardía, una especie de

34 Stephen J. Gould, La vida maravillosa: Burgess Shale y la naturaleza de la historia (Barcelona: Crítica, 1991), 31-40, citado por Arthur Peacocke, op. cit., 52-53. 
accidente cósmico, solo una fruslería en el árbol de Navidad de la evolución"35. Pero contando con estas posiciones que desestabilizan la concepción tradicional de una creación orientada hacia la creación de los seres humanos, los científicos admiten cierto tipo de tendencias o propensiones de la creación ${ }^{36}$ tales como la complejidad, la capacidad de procesar y almacenar información, el dolor y el sufrimiento y la conciencia refleja y el lenguaje. Estas tendencias nos ayudan a entender mejor el proceso evolutivo y no son "en absoluto misterios en el sentido de que requieran explicación alguna no naturalista"37. En lo que respecta al dolor hay que señalar que este es condición necesaria para la supervivencia de los seres vivos. No es por tanto consecuencia de ciertas flaquezas o caídas humanas, aunque indudablemente en muchos casos lo es, sino condición necesaria para el desarrollo de la evolución.

En cuarto lugar, "la evolución biológica es costosa, pues implica dolor, sufrimiento, depredación y muerte" ${ }^{\prime 38}$. El surgimiento de nuevos organismos precisa la muerte de otros: las plantas se alimentan de materiales inorgánicos y los animales de las plantas y de otros animales. La cadena alimenticia y la necesidad de que desaparezcan modelos viejos para que surja lo nuevo es la lógica de la evolución, porque la vida nueva por la muerte antigua es inevitable en un mundo finito compuesto de sillares básicos comunes (átomos, moléculas, macromoléculas) que tienen propiedades fijas.

La descripción de estos cuatro procesos que se pueden constatar en el desarrollo evolutivo, afectan la imagen de Dios que tenemos. Si el dolor, el sufrimiento y la muerte son inherentes a ella żno podía el Creador idearse otra manera de crear que no implicara todas esas realidades negativas? Los datos biológicos nos permiten entender que no hay otra manera para que surja la vida y se mantenga la

36 Karl Popper, Un mundo de propensiones (Madrid: Tecnos, 1992), 30. Citado por Arthur Peacocke, op. cit., 54 .

37 Arthur Peacocke, op. cit., 56

38 Ibíd., 60. 
creación continua. Si eso es así, hay que afirmar respecto de Dios que está sufriendo en, con y bajo los procesos creativos del mundo con su costoso despliegue temporal. En otras palabras, nosotros no somos meros juguetes de los dioses, o de Dios, sino que, como creaturas co-creadoras, compartimos el sufrimiento de un Dios que se compromete en el proceso de producir lo nuevo mediante un autosacrificio costoso. Si ya la teología hablaba de ese autovaciamento o autodespojo (Kénosis) de Dios para darle espacio a la creación, lo que nos aportan los datos de la biología es que esa autolimitación divina implica un compromiso costoso y sufriente con las creaturas en orden a la realización definitiva de los designios divinos y su consumación definitiva.

Pero en todo esto lo que se juega no es un sufrimiento destructivo sino un sufrimiento propio de quien ama. La afirmación de que Dios es amor, se hace real en esta concepción de Dios a la luz de los datos de la evolución, porque la creación existe por el sufrimiento que resulta como fruto del poder creativo del amor. Y, en definitiva, esta conclusión no solo proviene de los datos de la ciencia sino que desde la misma fe en Jesucristo se corroboran: "Pues mientras él vivió en la tierra fue muy vulnerable a los poderes que se agitaban a su alrededor, bajo los cuales acabó sucumbiendo con terrible sufrimiento $y$, desde su punto de vista humano, en el abandono de una muerte trágica"39.

\subsection{Kénosis como acción creadora}

Ya hablamos en el apartado sobre la humildad de Dios de la necesidad de abordar el tema del poder porque la creación parece implicar un Dios todopoderoso. En ese apartado afirmábamos que ese poder es en entrega y servicio, es decir, en actitud humilde testimoniada en la vida histórica de Jesucristo. Aquí queremos seguir profundizando ese tópico afirmando que el poder divino no puede 
separarse del amor ya que, por una parte, la creación es obra de un poder que excede el poder de todas las creaturas, pero, por otra parte, eso no es suficiente porque es necesario hacerse la pregunta: ¿̇cuál es el sentido de esta creación? ¿̇Para qué Dios la creó? La respuesta no puede ser otra que su amor infinito que excede las relaciones de las tres personas divinas y se proyecta sobre todo lo creado. Por tanto el poder y el amor están íntimamente relacionados porque "un amor sin poder sería propio de un dios que fuese compasivo pero impotente espectador de la historia del mundo. El poder sin el amor correspondería a un dios que fuese el tirano cósmico dominador y controlador implacable de toda la historia"40. Mantener por tanto la debida tensión entre el poder y el amor es tarea de la teología, sabiendo lo limitado de sus afirmaciones porque solo cuenta para tratar misterios inabarcables como es Dios mismo, con el lenguaje humano que es finito. Pero esa dificultad no nos deja en una teología apofática -aunque reconozcamos su valor y su necesidad-sino que nos impulsa a decir alguna palabra, reconociendo siempre su precariedad y limitación y, por tanto, su formulación como hipótesis y búsqueda, más que como afirmación definitiva y última. Este es el propósito que pretendemos aquí.

Tenemos que partir de la afirmación ya repetida a lo largo de este escrito, de la evolución del universo, de su ser una creación en proceso: "nosotros vivimos en un planeta de segunda generación que gira alrededor de una estrella de segunda generación, efectos uno y otra de la condensación de nubes de gas y de los detritos de las explosiones de supernovas de la primera generación"41. Esta convicción de una creación "haciéndose" corrobora la idea de un Creador que le permite a su creación "hacerse a sí misma (...) el curso del despliegue de la creación lo comparte Dios con sus creaturas, las cuales tienen, otorgados pero no dictados por Él, papeles que

40 John Polkinghorne, "Creación kenótica y acción divina" en La obra del amor. La creación como kénosis, op. cit., 127-146. 128.

41 Ibíd., 131. 
representar en su fecunda realización"42. En otras palabras, lo que la teología actual intenta postular para responder al proceso evolutivo de la creación es que junto a la creación ex nihilo existe la creación continua. La primera preserva la trascendencia de Dios la cual no puede ser puesta en cuestión si esperamos un destino final de la creación distinto de la ruina total. La segunda nos permite poner en diálogo la ciencia y la fe, exigencia actual de la teología.

Detrás de la posibilidad de una creación continua está la concepción kenótica de la creación. Por una parte, exige admitir el despliegue flexible y abierto a la causalidad de las creaturas, o, dicho en otros términos, concebir los seres humanos como "co-creadores creados" $^{\prime 43}$. Por otra, ese compartir el poder de manera kenótica libra a Dios de la responsabilidad única de todo lo que sucede y abre a la aceptación de un coste inherente al proceso evolutivo que no puede evitarse. Finalmente, puede advertirse que afirmar una creación continua supone también que el Creador pueda ser parte de ese despliegue evolutivo. Por tanto "la creación kenótica y la acción divina son las dos caras de la misma moneda teológica (...) si el proceso evolutivo es generado por la interacción del azar (o sea la contingencia histórica) y la necesidad (o sea la regularidad legal), su Creador habrá de estar tan presente en la contingencia como en la regularidad"44. Es decir, el Dios Padre que invocamos no solo es fundamento de la creación sino que actúa en ella en su despliegue evolutivo. Ahora bien, ¿̇cómo conciliar adecuadamente estas afirmaciones si la ciencia da cuenta de la regularidad de los procesos naturales? ¿̇de qué manera interviene Dios? Aquí es donde ciencia y teología han de dialogar pero ambas han de mantenerse flexibles si pretenden tener un diálogo fecundo.

42 Ibíd., 132.

43 Philip Hefner, The Human Factor (Minneapolis: Fortress Press, 1993), citado por John Polkinghorne, op. cit., 133.

44 John Polkinghorne, op. cit., 134. 
La creación, en términos del Dios kenótico que hemos expuesto a lo largo de este escrito, nos lleva a profundizar aún más en los diferentes tipos de kénosis que pueden darse en la relación amorosa del Creador con la creación. Señalamos cuatro, a saber ${ }^{45}$ :

(1) kénosis de la omnipotencia: todo lo que sucede es permitido por la providencia general, pero no todo acorde con la voluntad divina porque permite la existencia y acción de otros seres creados.

(2) Kénosis de la simple eternidad: sin negar la eternidad de Dios se asume la temporalidad como parte inherente a la creación. Siendo así, el Creador se relaciona con las circunstancias variables de una creación temporal. Él ha asumido libremente la experiencia del tiempo. Esta postura es propia de la teología procesual y, en cierta medida, está avalada por la interpretación de la kénosis en Flp 2 en la que la naturaleza eterna de Dios asume la temporalidad histórica en la encarnación del Hijo de Dios.

(3) Kénosis de la omnisciencia: si se afirma el compromiso del Creador con lo temporal se puede afirmar que Dios conoce todo lo que puede ser conocido pero, al mismo tiempo, no conoce aún todo lo que quizás llegue después a ser cognoscible. Es decir, la omnisciencia divina es auténtica pero no absoluta. A pesar de lo controvertida que resulta esta afirmación -al contrastarla con la teología clásica que afirma el conocimiento de Dios de la totalidad de la historia temporal-, cada día es más aceptada entre la comunidad teológica que afronta estos temas ${ }^{46}$. La auténtica omnisciencia representa una limitación en Dios, pero una limitación que ha sido asumida desde dentro de la naturaleza divina y no impuesta desde fuera.

(4) Kénosis del estatus causal: partiendo de la encarnación del Verbo en la que Dios no solamente actúa presente en las causas segundas, sino de hecho en la persona de Jesús, se propone esa manera

46 Para una aproximación a los teólogos dedicados a este diálogo con la ciencia Cf. John Polkinghorne, Scientists and Theologians (Londres: SPCK Society for promoting Christian Knowledge, 1996). 
fáctica del actuar de Dios que algunos consideran hoy, atribuible al Espíritu. Es decir, Dios no solo ejercería su providencia divina de manera energética sino también informativamente, en la encarnación del Verbo y en la acción histórica del Espíritu.

Por último, algunos autores proponen que la acción creadora de Dios está abierta a la novedad. Es decir, que el desarrollo evolutivo de la creación puede traer realidades nuevas que ni el mismo Dios ha pensando de antemano. Para estos autores, "Dios no ha de estar siempre aburridamente restringido a no hacer nada nuevo"47. Sea como sea, lo que podemos afirmar en este apartado es que la acción de Dios se ejerce en este proceso evolutivo de la creación de manera kenótica pero no por eso menos real.

Todas estas afirmaciones, como ya dijimos, son búsquedas y posturas teológicas que están en debate y que no podemos concebir como plenamente aceptadas y, menos aún, incorporadas a la reflexión teológica sobre Dios como hechos ya dados. Responden a los planteamientos de los autores citados, con las propias reflexiones que ellos nos suscitan y, en ese sentido, las presentamos aquí, con el ánimo de suscitar el debate y avanzar en la tarea que convoca a los teólogos y teólogas cuando se preguntan por el sentido de la creación y la imagen de Dios que de ella se deriva.

\subsection{Kénosis y perspectiva de género}

La riqueza de la reflexión teológica nos muestra realmente cómo la kénosis puede abordarse desde perspectivas cristológicas y trinitarias hasta desembocar en la reflexión sobre la creación y las implicaciones de esta para la omnipotencia divina. Sin embargo, no todas las reflexiones desembocan en la misma realidad porque dependen del punto de partida que tome cada teólogo o teóloga. Pero todas ellas nos permiten acercarnos al misterio divino que siempre 
es mayor que lo que nuestros conceptos y aproximaciones pueden aportar.

En esta misma línea, no es menos importante añadir una reflexión sobre la categoría kénosis desde la perspectiva de género. ${ }^{48}$ En efecto, la teología feminista ha reflexionado en las últimas décadas sobre cómo esa llamada al vaciamiento de sí o a la autohumillación divina puede no favorecer el trabajo de las mujeres por recuperar su autoestima y protagonismo en la historia actual. Surge por tanto la pregunta legítima de si este proyecto de valorización de lo kenótico, como categoría explicativa del mismo ser de Dios en relación con una creación en proceso, puede ser negativo para la tarea feminista. Intentaremos hacer aquí una aproximación breve ${ }^{49}$.

La primera reflexión surge en torno a la libertad. Como hemos visto en varias de las reflexiones anteriormente expuestas, el diálogo entre un Dios creador y una creación en proceso es posible en la medida que la libertad de las creaturas pueda ser real y efectiva. Pero es aquí donde precisamos hacer una aclaración. Esa libertad no está ajena a condicionamientos de todo tipo y, por tanto, a los de género. En el afán de asegurar que Dios actúa en el mundo a través de sus creaturas y acompaña el proceso evolutivo, no se puede olvidar que en esta responsabilidad compartida de ser co-creadores de este mundo, han de revisarse todas las connotaciones de poder que supongan la subordinación de unos seres frente a otros, incluidas las que se han llamado socialmente machismo, patriarcado o androcentrismo presentes en nuestra configuración del mundo actual. Más aún, la teóloga Elisabeth Schüssler Fiorenza acuñó el neologismo Kyriarcado ${ }^{50}$ para expresar el gobierno del emperador/

48 Sarah Coakley, "Kénosis: significados teológicos y connotaciones de género" en John Polkinghorne, La obra del amor. La creación como kénosis, op. cit., 247-267, 248.

49 Para un estudio más extenso: Amparo Novoa y Consuelo Vélez, op. cit. y Sarah Coakley, "Kenosis and Subversion: On the Repression of Vulnerability en Christian Feminist Writing" en Margaret Daphne Hampsom (ed), Swallowing a Fishbone? Feminist Theologians Debate Christianity (Londres: SPCK, 1996), 82-111.

50 Elisabeth Schüssler Fiorenza, Cristología feminista crítica. Jesús, Hijo de Miriam, Profeta de la Sabiduría (Madrid: Trotta, 2000), 32. 
amo/señor/padre/esposo sobre sus subordinados. Con ese término se quiere expresar que no todos los varones dominan y explotan a las mujeres indiferenciadamente, sino que existe un marco intelectual y una ideología cultural que produce una compleja pirámide social de dominaciones y subordinaciones graduales, donde unos ejercen el poder sobre otros, pudiendo ser varones y/o mujeres los que están en las diversas escalas de subordinación.

Una segunda reflexión supone revisar el significado de abnegación kenótica. En efecto, históricamente esta actitud se ha usado para favorecer la dominación de unos sobre otros, especialmente de los varones sobre las mujeres. Por eso la teología feminista reivindica una manera de ser varón y mujer donde el destino de las mujeres no sea el sufrimiento y el del varón no sea el poder. Ambos están llamados a salir de sí para encontrar al otro y para llevar a término la responsabilidad co-creadora, pero sin perder su autoestima y su propia dignidad. Sin duda los varones necesitan hacer un proceso de no pensar el poder en términos de dominación y jerarquía, pero las mujeres necesitan creer que pueden estar en instancias de decisión y llevar por sí mismas las riendas de sus vidas. Estas afirmaciones pueden resultar anacrónicas en ámbitos académicos donde la presencia de la mujer se va fortaleciendo, pero no en los ámbitos más vulnerables donde la mentalidad androcéntrica sigue presente.

La kénosis nos invita a vivir este salir de sí para una vivencia de la alteridad donde sea reconocida profundamente la irrepetibilidad del otro, sin querer encasillarlo en estereotipos femeninos o masculinos que reproduzcan subordinación y dominio.

Finalmente, cabe anotar que estas relaciones de subordinación se extienden más allá del ámbito genérico para referirse a la dominación que se ha ejercido sobre la naturaleza, en término de explotación irracional y falta de conservación y cuidado, viéndonos abocados, hoy en día, a un deterioro de la misma y a una alarma real de las consecuencias que se derivan de ella. Sin una actitud de cambio y respeto hacia la naturaleza, de valorar la comunión a la que se 
está llamado con ella, no podemos romper ese círculo de poder que traiciona la imagen de un Dios creador que renunciando al ejercicio del poder, en esos términos, es capaz de crear y sostener el cosmos desde el horizonte de la libertad, el amor, el respeto y la comunión entre todos los seres humanos y de éstos con la naturaleza y todos los demás seres vivos.

Estas reflexiones sobre la perspectiva de género en la categoría kénosis enriquece la reflexión sobre un Dios capaz de salir de sí para dar origen a este universo tal y como lo explica hoy la ciencia, porque nos hace caer en la cuenta de que en ningún momento Dios sale de sí para subordinarse a las creaturas, sino que es capaz de mantener el reconocimiento del otro sin la pérdida de sí. En otras palabras, es el reconocimiento de la "alteridad sin que se encierre al otro en una categoría preconcebida, o se le reduzca a un artículo de necesidad personal. La integridad moral del otro solamente es mantenida por un acto deliberado de dejarle espacio, o como dice Irigaray, por el mutuo éxtasis -o salir de sí mismo- que respeta la diferencia del otro sin la pretensión egoísta de controlarle" ${ }^{51}$.

Es una imagen sugerente para la construcción de nuevas relaciones genéricas que favorezcan el desarrollo integral de varones y mujeres en vistas a la construcción de una sociedad más inclusiva y democrática, más fraternal/sororal y justa y con nuevas relaciones con el cosmos que permitan la acción creadora de Dios y co-creadora de toda la humanidad en el horizonte del cuidado, la sustentabilidad y la preservación.

\section{A modo de conclusión}

El recorrido que hemos hecho ha respondido al deseo de comenzar a incursionar por estos nuevos caminos que hoy desafían a la teología. Son muchas y profundas las reflexiones que ya se están

51 Sarah Coakley, op.cit, 266. Cf. Lucy Irigaray, "Questions to Emmanuel Lévinas" en Margaret Whitford (ed.), The Irigaray Reader (Oxford: Blackwell, 1991), 180. 
elaborando a este propósito, pero no son fáciles de integrar y menos de tener un criterio claro sobre la validez y veracidad de las mismas. Pero son pistas de reflexión que invitan a seguir buscando articulación entre los desarrollos científicos y la experiencia de fe y, por tanto, es una tarea que no puede esquivarse.

Definitivamente una visión científica del mundo ha de acompañarnos en estos tiempos actuales para poder responder mejor a las exigencias de su devenir. En momentos en que estamos tomando conciencia sobre el deterioro del planeta, de la responsabilidad enorme que nos cobija de preservar la creación para las generaciones futuras y de seguir avanzando en los descubrimientos para afrontar problemas tan reales como enfermedades y todo lo que impide el desarrollo pleno para favorecer la vida, la fe ha de prestar su servicio imprescindible en el compromiso con un futuro que creemos está en manos de Dios y de su providencia pero que reconocemos hoy como puesto también en nuestras manos para llevarlo a feliz término.

Todas las explicaciones hechas a lo largo de este escrito sobre las posibilidades que ofrece la kénosis divina para entender una creación en proceso, iluminan de manera importante por dónde ha de ir nuestra responsabilidad en esta empresa. Sin una actitud kenótica como la del mismo Dios no podremos colaborar en esta creación que también es nuestra, porque el ansia de poder, el rechazo a todo dolor y sufrimiento y la incapacidad de establecer relaciones de equidad con los seres animados e inanimados, serán impedimentos con los que tropezaremos irremediablemente. Sin embargo, precisamente en el cultivo de esa misma actitud y la petición confiada de la gracia divina para conseguirla, vislumbramos la esperanza de un futuro donde no solo Dios esté creando continuamente, sino que los seres humanos nos dejemos crear y, al mismo tiempo, seamos colaboradores incondicionales de esa misma obra de amor.

Las hipótesis aquí trazadas no pueden ofrecernos respuestas definitivas pero sí señalan caminos por donde podamos seguir profundizando. Y esta tarea es urgente porque los seres humanos precisamos no solo 
hipótesis sino afirmaciones que puedan responder al "deseo irrestricto de conocer del ser humano" 52 . Por eso, atreverse a pensar en la kénosis de Dios nos obliga a cambiar la imagen del Dios todopoderoso; $y_{\text {, pensar }}$ en la kénosis de los seres humanos, nos permite constituirnos de otra manera, sumergiéndonos en el proyecto trinitario de una creación por amor en el que Dios nos ha hecho libres y confía en nuestra colaboración, para que poco a poco seamos también ese mismo amor que haga posible un universo recapitulado en Cristo, donde todo y todos entremos en esa comunión divina con Él (Cf. Ef 1,10; Col 3, 11).

\section{Bibliografía}

Balthassar, Hans Urs von. "El misterio pascual". En Mysterium Salutis, editado por Johannes Feiner y Magnus Lohrer. Madrid: Cristiandad, 1971: 143-331.

Barbour, Ian G. "El poder divino: un enfoque procesual". En La obra del amor. La creación como kénosis, editado por John Polkinghrone. Navarra: Verbo Divino, 2001: 21-43.

Brunner, Emil. Dogmatics. vol.2. Londres: Lutterwoerth Press, 1952.

Coakley, Sarah. "Kenosis and Subversion: On the Repression of Vulnerability en Christian Feminist Writing". En Swallowing a Fishbone? Feminist Theologians Debate Christianity, editado por Margaret Daphne Hampson. Londres: SPCK, 1996: 82-111.

. "Kénosis: significados teológicos y connotaciones de género". En La obra del amor. La creación como kénosis, editado por John Polkinghrone. Navarra: Verbo Divino, 2001: 247-267.

Einstein, Albert. Ideas and Opinions. New York: Modern Library, 1994.

52 Bernard Lonergan, Insight. Estudio sobre la comprensión humana (Salamanca: Sígueme, 1999), 17. 
Fee, Gordon D., (ed). Paul's letter to the Philippians. The New International Commentary on the New Testament. Michigan: Wn.B. Eerdmans Publisching Co., 1995.

Gould, Stephen J. La vida maravillosa: Burgess Shale y la naturaleza de la historia. Barcelona: Crítica, 1991.

Grelot, Adán. "Deux notes critiques sur Philip 2, 6-11". Bíblica 54 (1973): 169-186.

Haught, John F. Cristianismo e ciência. Para uma teologia da natureza. São Paulo: Paulinas, 2010.

Hefner, Philip. The Human Factor. Minneapolis: Fortress Press, 1993.

Lonergan, Bernard. Método en Teología. Salamanca: Sígueme, 1994. . Insight: Estudio sobre la comprensión humana. Salamanca: Sígueme, 1999.

Moltmann, Jürgen. "La kénosis divina en la creación y consumación del mundo". En La obra del amor. La creación como kénosis, editado por John Polkinghrone. Navarra: Verbo Divino, 2008: 181-196.

. God in Creation. A New Theology of Creation and the Spirit of God. San Francisco: Harper \& Row, 1985.

Novoa, Amparo y Vélez, Consuelo. "La categoría Kénosis. Una lectura desde la perspectiva de género". En Theologica Xaveriana 169, Año 60/1 (2010): 159-190.

Peacocke, Arthur. "El coste de la nueva vida" En La obra del amor. La creación como kénosis, editado por John Polkinghrone. Navarra: Verbo Divino, 2001: 45-70.

Polkinghorne, John C. Scientists and Theologians. Londres: SPCK (Society for promoting Christian Knowledge), 1996.

. "Creación kenótica y acción divina". En La obra del amor. La creación como kénosis, editado por John Polkinghrone. Navarra: Verbo Divino, 2001: 127-146. 
Popper, Karl. Un mundo de propensiones. Madrid: Tecnos, 1992.

Scholem, Gershom. Major Trends in Jewish Mysticism. New York: Schocken, 1954.

Schüssler Fiorenza, Elisabeth. Cristología feminista crítica. Jesús, Hijo de Miriam, Profeta de la Sabiduría. Madrid: Trotta, 2000.

Temple, Frederick. "Conferencias Bampton de 1885". Michigan: Baker Book House, 1961.

Whitford, Margaret (ed.). The Irigaray Reader. Oxford: Blackwell, 1991.

Recibido: 25 de julio de 2011 Aceptado: 21 de septiembre de 2011 